\title{
Amyloid- $\beta$ plaque formation and reactive gliosis are required for induction of cognitive deficits in App knock-in mouse models of Alzheimer's disease
}

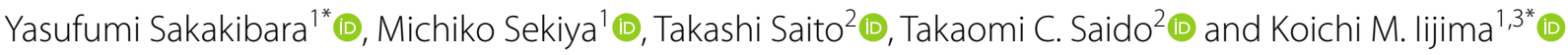

\begin{abstract}
Background: Knock-in (KI) mouse models of Alzheimer's disease (AD) that endogenously overproduce A $\beta$ without non-physiological overexpression of amyloid precursor protein (APP) provide important insights into the pathogenic mechanisms of AD. Previously, we reported that App ${ }^{N L-G-F}$ mice, which harbor three familial AD mutations (Swedish, Beyreuther/Iberian, and Arctic) exhibited emotional alterations before the onset of definitive cognitive deficits. To determine whether these mice exhibit deficits in learning and memory at more advanced ages, we compared the Morris water maze performance of $A p p^{N L-G-F}$ and $A p p^{N L}$ mice, which harbor only the Swedish mutation, with that of wild-type (WT) C57BL/6J mice at the age of 24 months. To correlate cognitive deficits and neuroinflammation, we also examined $A \beta$ plaque formation and reactive gliosis in these mice.

Results: In the Morris water maze, a spatial task, 24-month-old App $p^{\text {NL-G-F/NL-G-F }}$ mice exhibited significantly poorer spatial learning than WT mice during the hidden training sessions, but similarly to WT mice during the visible training sessions. Not surprisingly, App ${ }^{N L-G-F / N L-G-F}$ mice also exhibited spatial memory deficits both 1 and 7 days after the last training session. By contrast, 24-month-old $A p p^{N L N L}$ mice had intact spatial learning and memory relative to WT mice. Immunohistochemical analyses revealed that 24-month-old App $p^{N L-G-F / N L-G-F}$ mice developed massive A $\beta$ plaques and reactive gliosis (microgliosis and astrocytosis) throughout the brain, including the cortex and hippocampus. By contrast, we observed no detectable brain pathology in $A p p^{N L N L}$ mice despite overproduction of human $A \beta 40$ and A $\beta 42$ in their brains.

Conclusions: $A \beta$ plaque formation, followed by sustained neuroinflammation, is necessary for the induction of definitive cognitive deficits in App-KI mouse models of AD. Our data also indicate that introduction of the Swedish mutation alone in endogenous APP is not sufficient to produce either AD-related brain pathology or cognitive deficits in mice.
\end{abstract}

Keywords: Alzheimer's disease, Amyloid precursor protein, Knock-in mouse model, Cognitive deficits, Neuroinflammation

\footnotetext{
*Correspondence: bara@ncgg.go.jp; iijimakm@ncgg.go.jp

${ }^{1}$ Department of Alzheimer's Disease Research, Center for Development

of Advanced Medicine for Dementia, National Center for Geriatrics

and Gerontology, Obu, Aichi 474-8511, Japan

Full list of author information is available at the end of the article
}

C The Author(s) 2019. This article is distributed under the terms of the Creative Commons Attribution 4.0 International License (http://creativecommons.org/licenses/by/4.0/), which permits unrestricted use, distribution, and reproduction in any medium, provided you give appropriate credit to the original author(s) and the source, provide a link to the Creative Commons license, and indicate if changes were made. The Creative Commons Public Domain Dedication waiver (http://creativecommons.org/ publicdomain/zero/1.0/) applies to the data made available in this article, unless otherwise stated. 


\section{Background}

Authentic animal models for Alzheimer's disease (AD) research are of vital importance for investigating the molecular mechanisms and testing potential therapeutic approaches to $\operatorname{AD}[1,2]$. Several transgenic mouse lines overexpressing amyloid precursor protein (APP) that recapitulate amyloid- $\beta$ (A $\beta)$ deposition and the accompanying behavioral deficits have been instrumental to AD research [3-6]. However, these mice may also exhibit phenotypes because they overproduce various APP fragments in addition to $A \beta$ [7-9].

To overcome this problem, alternative mouse models have been generated via knock-in (KI) of a humanized $\mathrm{A} \beta$ sequences harboring familial AD mutations (Swedish $(\mathrm{NL})$, Beyreuther/Iberian (F), and Arctic (G)) in order to model $A \beta$ amyloidosis without non-physiological overexpression of APP [10]. In $A p p^{N L-G-F}$ mice, which harbor all three mutations, $A \beta$ amyloidosis is aggressive, and neuroinflammation is observed in subcortical structures as well as cortical regions [10-12]. By contrast, $A p p^{N L}$ mice that carry only the Swedish mutation produce significantly higher levels of $A \beta 40$ and $A \beta 42$ without overt $A D$-related brain pathology such as extracellular $A \beta$ plaques or neuroinflammation $[10,11,13]$. None of these $A p p$-KI mice exhibit tau pathology or severe neuronal loss, suggesting that they are suitable models for preclinical AD [9].

Previously, we reported that $A p p^{N L-G-F}$ mice exhibit anxiolytic-like phenotypes in the elevated plus maze task at 6 months of age, as well as a subtle decline in spatial learning ability during the acquisition session of the Barnes maze task at 8 months [14]. These results suggest that $A p p^{N L-G-F}$ mice develop emotional alterations prior to the emergence of the definitive cognitive deficits. By contrast, $A p p^{N L}$ mice do not undergo overt cognitive decline prior to 8 months of age [14], although it remains to be seen whether these $A p p$-KI mice exhibit learning and memory deficits at more advanced ages.

In this study, we assessed the performance of $A p p^{N L-G-F}$, $A p p^{N L}$, and wild-type (WT) C57BL/6J mice in a spatial task at the age of 24 months. To correlate cognitive deficits and neuroinflammation, we also examined $A \beta$ plaque formation and reactive gliosis in these mice. Our results demonstrate that $\mathrm{A} \beta$ deposits, followed by sustained neuroinflammation, is required for induction of definitive cognitive deficits in App-KI mouse models of AD.

\section{Results \\ $A p p^{N L-G-F / N L-G-F}$ mice exhibit spatial learning deficits and reduced memory function in the Morris water maze task}

The Morris water maze (MWM) is one of the most commonly used paradigms for assessing hippocampal-dependent spatial learning and memory in mouse models of $\operatorname{AD}[5,15]$. In this task, mice are required to use extra-maze cues to learn the location of a platform submerged below the water surface. During the initial training session, when the platform can be seen ("visible training"), the motor and visual capacities of the mice were assessed (Fig. 1a). Subsequently, the mice were trained to acquire the spatial location of a platform when the platform was not visible ("hidden training") (Fig. 1a). One day after the sixth session of hidden training, a probe test (Probe test 1) was conducted without a platform to determine whether mice had learned the location of the platform using extra-maze cues (Fig. 1a). These mice were also subjected to a second probe test (Probe test 2) 7 days after the seventh session of hidden training (Fig. 1a).

To assess motor and visual capabilities, mice were compared across 4-day visible training sessions, during which the platform was indicated by a black cubic landmark (Fig. 1a). $A p p^{N L-G-F / N L-G-F}, A p p^{N L / N L}$ and WT mice performed equally well in these sessions: latency (Fig. 1b; $F[2,41]=0.12, p=0.890$ ) and distance (Fig. 1c; $F[2,41]=0.07, p=0.929)$ to reach the platform, as well as swimming speed (Fig. 1d; $F[2,41]=0.59, p=0.561$ ), were similar among genotypes. As the training progressed, all genotypes reached the visible platform in the minimum amount of time via the shortest path, as reflected by significant reductions in latency (Fig. $1 b ; F[1.3,54]=45.75$, $p<0.001$ ) and distance (Fig. 1c; $F[1.5,60.9]=39.80$, $p<0.001)$ across the training. Swimming speed over the course of training was significantly increased in all genotypes (Fig. 1d; $F[3,123]=26.73, p<0.001$ ). These results

\footnotetext{
(See figure on next page.)

Fig. 1 Learning performance in $A p p^{N L-G-F / N L-G-F}$ and $A p p^{N L / N L}$ mice during training sessions in the Morris water maze task. a Schematic timeline of the Morris water maze (MWM) task. Mice received visible training for 4 days (4 trials per day) to assess motor and visual capabilities, followed by hidden training for 7 days (4 trials per day) to assess spatial learning ability. Two probe tests were conducted at 1 day after the sixth session (Probe test 1) and at 7 days after the seventh session of the hidden training (Probe test 2) to assess spatial memory performance. $\mathbf{b}-\mathbf{d}$ In the visible training sessions, $A p p^{N L-G-F / N L-G-F}$ and $A p p^{N L / N L}$ mice performed equally as well as WT mice. e and $\mathbf{f}$ During the hidden training sessions, App ${ }^{N L-G-F / N L-G-F}$ mice significantly spent more time and travelled a longer distance to reach the submerged platform than WT mice. $\mathbf{g} A p p^{N L-G-F / N L-G-F}$ mice significantly exhibited lower path efficiency relative to WT mice. $\mathbf{h}$ Swimming speed did not differ between App ${ }^{N L-G-F / N L-G-F}$ and WT mice. e-h Spatial learning ability in $A p p^{N L / N L}$ mice was equivalent of that in WT mice. $\mathrm{n}=17 \mathrm{WT}(\mathrm{B} 6 \mathrm{~J}), \mathrm{n}=11 \mathrm{Ap} p^{\mathrm{NL} / N L}, \mathrm{n}=16 \mathrm{App} p^{N L-G-F / N L-G-F}$
} 
a

(Days)

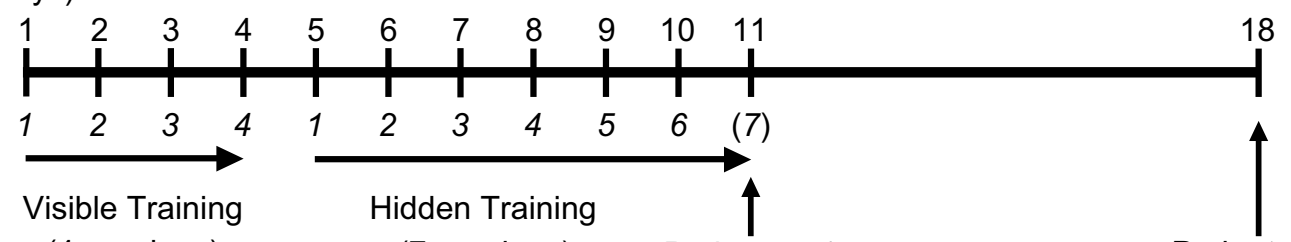

(4 sessions)

(7 sessions)

Probe test 1

Probe test 2

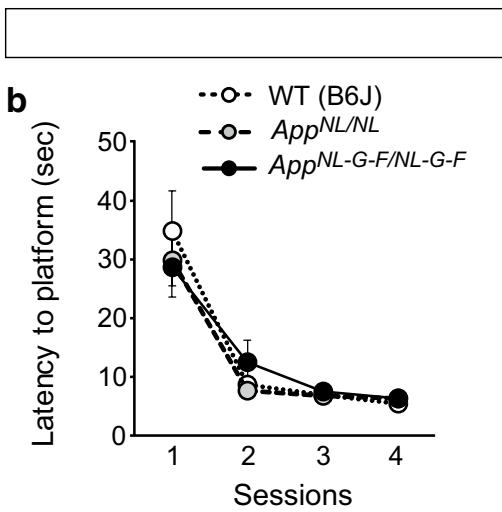

\section{Visible Training}
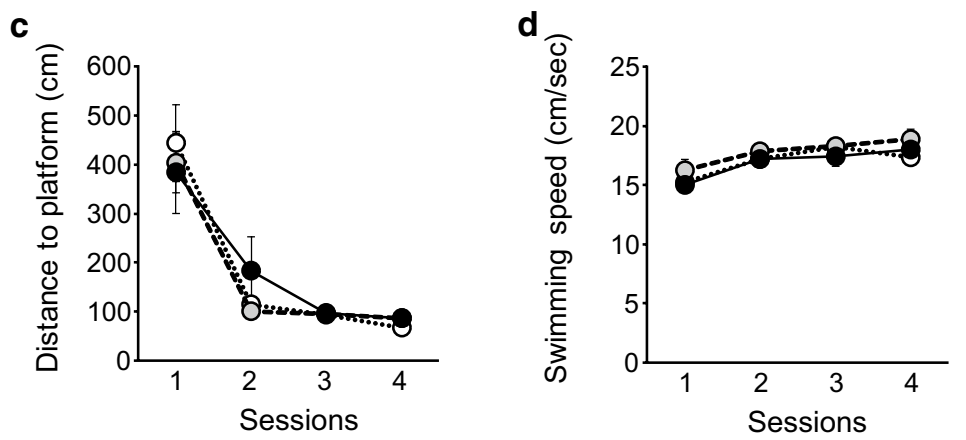

\section{Hidden Training}

e

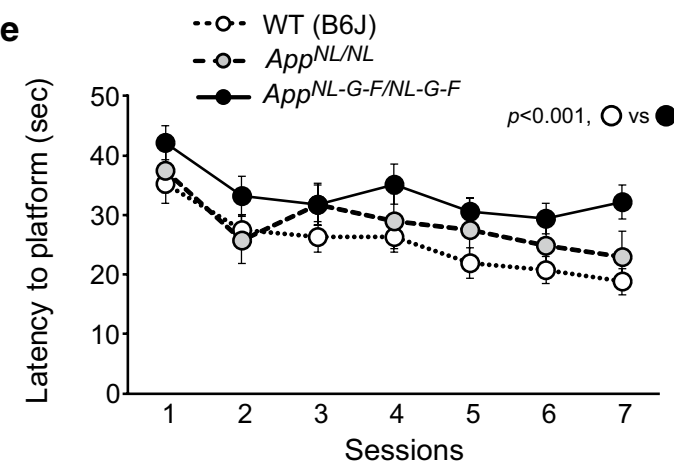

g

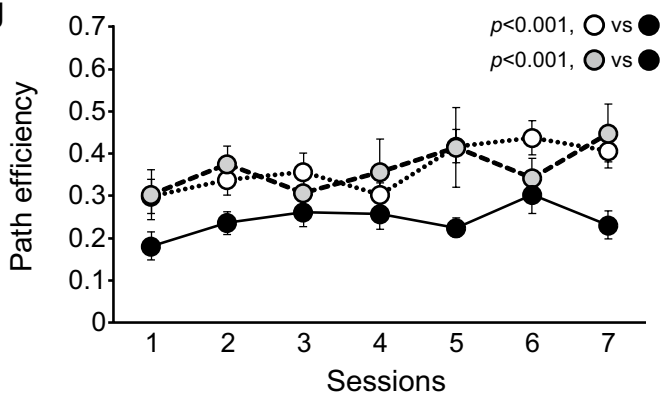

f

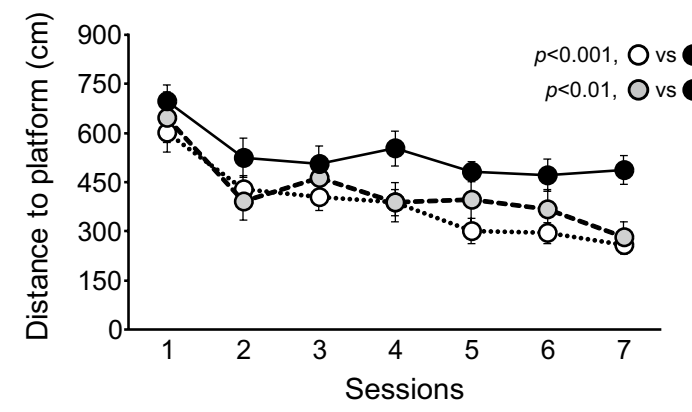

h

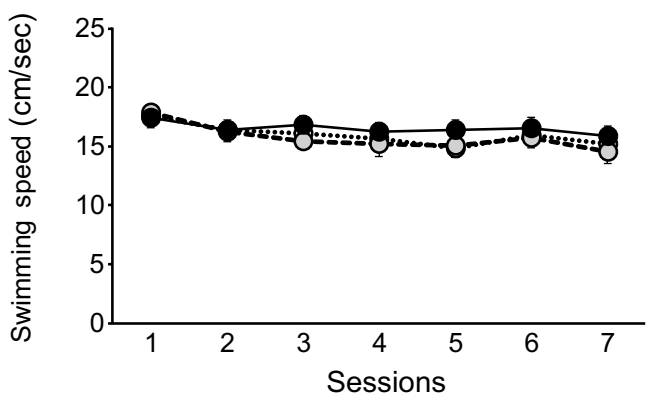

indicate that swimming and visual abilities were comparable among $A p p^{N L-G-F / N L-G-F}, A p p^{N L / N L}$, and WT mice at 24 months of age.
Following the visual training sessions, mice were trained to find a submerged platform during 7-day hidden training sessions (Fig. 1a). $A p p^{N L-G-F / N L-G-F}$ mice spent more 
time (Fig. 1e; $F[2,41]=7.88, p=0.001$, post hoc, WT vs. $\left.A p p^{N L-G-F / N L-G-F}, p<0.001\right)$ and travelled a longer distance (Fig. 1f; $F[2,41]=15.50, p<0.001$, post hoc, WT vs. $\left.A p p^{N L-G-F / N L-G-F}, p<0.001\right)$ to reach the platform than WT mice across the training. Moreover, relative to WT mice, $A p p^{N L-G-F / N L-G-F}$ mice exhibited lower path efficiency, as determined by the ratio of the actual distance to the ideal path that the mice could have taken to reach the platform (Fig. 1g; $F[2,41]=18.66, p<0.001$, post hoc, WT vs. $\left.A p p^{N L-G-F / N L-G-F}, p<0.001\right)[16,17]$, indicating that spatial accuracy was affected in these mice. Swimming speed did not differ between $A p p^{N L-G-F / N L-G-F}$ and WT mice (Fig. 1h; $F[2,41]=0.36, p=0.700)$, suggesting that difference in latency was not due to a difference in the ability to swim. Our data also revealed that $A p p^{N L-G-F / N L-G-F}$ mice could still learn the location of the hidden platform, as these mice exhibited decreases in latency (Fig. 1e; WT, $F[3.6$, $58]=4.61, p=0.004 ; A p p^{N L-G-F / N L-G-F}, F[3.4,51.3]=2.62$, $p=0.054$ ) and distance (Fig. 1f; WT, $F[3.2,51.0]=7.44$, $\left.p<0.001 ; A p p^{N L-G-F / N L-G-F}, F[3.8,57.4]=2.93, p=0.030\right)$ as the training progressed. Swimming speed over the course of training was significantly decreased in WT mice (Fig. 1h; WT, $F[6,96]=5.45, p<0.001$ ), while it remained constant in $A p p^{N L-G-F / N L-G-F}$ mice throughout the sessions $\left(A p p^{N L-G-F / N L-G-F}, \quad F[2.9,43.9]=2.18, p=0.106\right)$. Taken together, these results suggest that 24-month-old $A p p^{N L-}$ $G-F / N L-G-F$ mice exhibited a significant decline in the ability to learn the spatial location of a submerged platform.

In Probe test 1 (Fig. 1a), $A p p^{N L-G-F / N L-G-F}$ mice spent less time in the target quadrant than WT mice (Fig. 2a; $F[2,41]=4.23, p=0.021$, post hoc, WT vs. $A p p^{N L-G-F /}$ $N L-G-F, p=0.025)$, although they still exhibited a preference for the target quadrant over non-target quadrants (Additional file 1: Fig. S1a; WT, $t(16)=-4.45, p<0.001$; $\left.A p p^{N L-G-F / N L-G-F}, t(15)=-2.14, p=0.049\right)$. In addition, the percentages of time spent in the target quadrant were significantly greater than the chance level for both $\mathrm{WT}$ and $A p p^{N L-G-F / N L-G-F}$ mice (Fig. 2a; WT, $t(32)=4.45$, $\left.p<0.001 ; A p p^{N L-G-F / N L-G-F}, t(30)=2.14, p=0.040\right)$. During Probe test 1 , although differences in the number of platform crossings between WT and $A p p^{N L-G-F / N L-G-F}$ mice did not reach statistical significance (Fig. $2 \mathrm{~b} ; F[2$, $41]=2.95, \quad p=0.064), A p p^{N L-G-F / N L-G-F}$ mice exhibited significantly longer proximity to the platform than WT mice (Fig. 2c; $F[2,41]=5.61, p=0.007$, post hoc, WT vs. $\left.A p p^{N L-G-F / N L-G-F}, p=0.005\right)$; this parameter is believed to provide a more sensitive evaluation of spatial memory performance $[18,19]$. The total distance travelled (Fig. $2 \mathrm{~d} ; F[2,41]=2.68, p=0.081$ ) and swimming speed (Fig. 2e; $F[2,41]=2.49, p=0.095$ ) in Probe test 1 did not differ between WT and $A p p^{N L-G-F / N L-G-F}$ mice, suggesting that the two genotypes had similar motor capability and motivation to search for the platform. Together, these results suggest that $A p p^{N L-G-F / N L-G-F}$ mice had reduced spatial memory 1 day after the last training session, but still exhibited a spatial bias toward the former location of platform.

In Probe test 2 (Fig. 1a), the percentage of time spent in the target quadrant was significantly lower in $A p p^{N L-}$ $G-F / N L-G-F$ mice than in WT mice (Fig. 2f; $F[2,41]=9.03$, $p<0.001$, post hoc, WT vs. $\left.A p p^{N L-G-F / N L-G-F}, p<0.001\right)$. In addition, $A p p^{N L-G-F / N L-G-F}$ mice did not exhibit a spatial bias toward the target quadrant over non-target quadrants (Additional file 1: Fig. S1b; WT, $t(16)=-3.30$, $\left.p<0.001 ; \quad A p p^{N L-G-F / N L-G-F}, \quad t(15)=1.70, \quad p=0.110\right)$. Moreover, unlike WT mice (Fig. 2f; WT, $t(32)=3.30$, $p=0.002)$, the percentage of time spent in the target quadrant by $A p p^{N L-G-F / N L-G-F}$ mice was comparable to the chance level (Fig. 2f; $A p p^{N L-G-F / N L-G-F}, t(30)=-1.70$, $p=0.099$ ). Furthermore, although the number of platform crossings during the test did not differ between WT and $A p p^{N L-G-F / N L-G-F}$ mice (Fig. $2 \mathrm{~g} ; F[2,41]=1.81$, $p=0.176$ ), the proximity to the platform was significantly higher in $A p p^{N L-G-F / N L-G-F}$ mice (Fig. $2 \mathrm{~h} ; F[2,41]=8.94$, $p<0.001$, post hoc, WT vs. $\left.A p p^{N L-G-F / N L-G-F}, p<0.001\right)$.

Total distance travelled (Fig. 2i; $F[2,41]=3.55$, $p=0.038$, post hoc, WT vs. $\left.A p p^{N L-G-F / N L-G-F}, p=0.102\right)$ and swimming speed (Fig. 2 j; $F[2,41]=3.13, p=0.054$ ) were comparable between $A p p^{N L-G-F / N L-G-F}$ and WT mice, providing further confirmation that motor capability and motivation did not differ between genotypes. These results suggest that $A p p^{N L-G-F / N L-G-F}$ mice could not retain the acquired spatial memory 7 days after the last training session.

Taken together, our findings indicate $A p p^{N L-G-F / N L-G-F}$ mice exhibit definitive deficits in spatial learning and memory at the age of 24 months.

\section{$A p p^{N L / N L}$ mice exhibit normal spatial learning and memory in the MWM task, even at $\mathbf{2 4}$ months of age}

$A p p^{N L / N L}$ mice exhibited motor and visual capabilities comparable to those of WT mice during the visible training sessions, as evidenced by the lack of a between-genotype difference in latency (Fig. 1b), distance (Fig. 1c) and swimming speed (Fig. 1d).

During the hidden training sessions, $A p p^{N L / N L}$ mice performed as well as WT mice: latency (Fig. 1e; post hoc, WT vs. $A p p^{N L / N L}, p=0.362$ ) and distance (Fig. 1f; post hoc, WT vs. $\left.A p p^{N L / N L}, p=0.450\right)$ did not differ between WT and $A p p^{N L / N L}$ mice. In addition, path efficiency was similar between $A p p^{N L / N L}$ and WT mice across the training (Fig. 1g; post hoc, WT vs. $A p p^{N L / N L}, p=0.999$ ), indicating that both genotypes reached the hidden platform with comparable spatial accuracy. Swimming speed in $A p p^{N L / N L}$ mice was also comparable to that in WT mice and significantly decreased throughout the sessions 

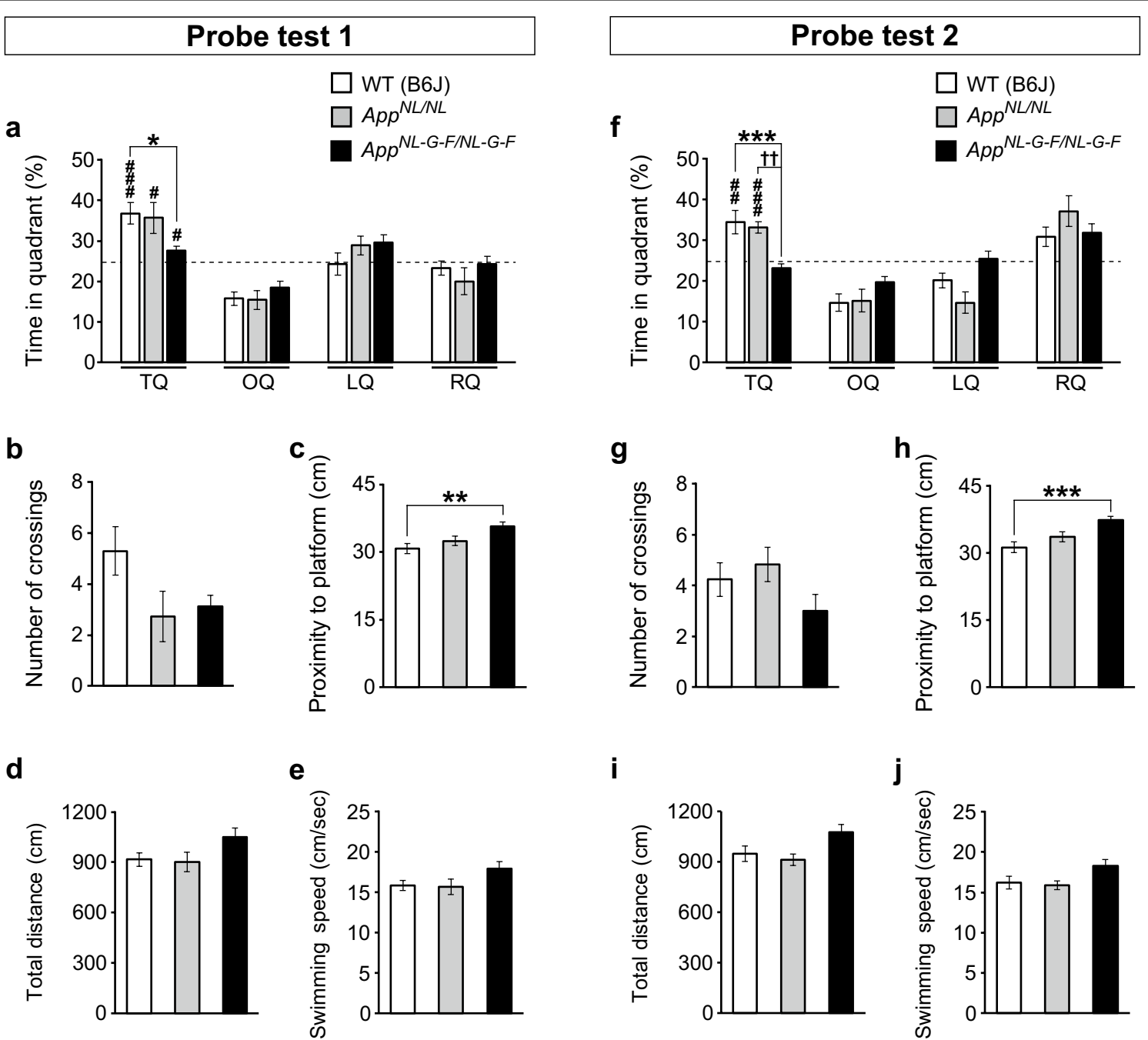

Fig. 2 Spatial memory in $A p p^{N L-G-F / N L-G-F}$ and $A p p^{N L N L}$ mice during probe tests in the Morris water maze task. a In Probe test 1, App ${ }^{N L-G-F / N L-G-F}$ mice spent less time in the target quadrant than WT mice. All genotypes spent significantly higher percentages of time in the target quadrant than predicted by chance ( $25 \%$, as indicated by dotted lines). b The number of platform crossings did not differ among genotypes. C App ${ }^{N L-G-F / N L-G-F}$ mice exhibited significantly longer proximity to the platform than WT mice. $\mathbf{d}$ and $\mathbf{e}$ The total distance travelled and swimming speed in Probe test 1 were similar among genotypes. $\mathbf{f}$ In Probe test 2, the percentage of time spent in the target quadrant was significantly lower in $A p p^{N L-G-F / N L-G-F}$ mice than in WT mice. The percentage of time spent in the target quadrant by App $p^{N L-G-F / N L-G-F}$ mice was comparable to the chance level (25\%). $\mathbf{g}$ The number of platform crossings during the test did not differ among genotypes. $\mathbf{h}$ The proximity to the platform was significantly higher in App ${ }^{\text {NL-G-F/ }}$ ${ }^{N L-G-F}$ mice. $\mathbf{i}$ and $\mathbf{j}$ Total distance travelled and swimming speed were comparable among genotypes. $\mathbf{a}-\mathbf{j}$ App ${ }^{N L / N L}$ mice had normal memory function at 1 and 7 days after the last training session. $n=17$ WT (B6J), $n=11$ App $^{N L N L}, \mathrm{n}=16$ App ${ }^{N L-G F / N L-G-F} .{ }^{*} p<0.05,{ }^{* *} p<0.01$, ${ }^{* * *} p<0.001$, versus WT (B6J). ${ }^{++} p<0.01$, versus $A p p^{N L / N L . ~}{ }^{\prime} p<0.05,{ }^{\#} p<0.01$, \#\# $p<0.001$, versus chance level

(Fig. $\left.1 \mathrm{~h} ; A p p^{N L / N L}, F[6,60]=5.40, p<0.001\right)$. Taken together, these results suggest that spatial learning ability in $A p p^{N L / N L}$ mice was equivalent of that in WT mice at 24 months of age.

In Probe test 1 , time spent in the target quadrant did not significantly differ between WT and $A p p^{N L / N L}$ mice (Fig. 2a; post hoc, WT vs. $A p p^{N L / N L}, p=0.955$ ). $A p p^{N L / N L}$ spent a significantly higher percentage of time in the target quadrant than would be predicted by chance $\left(A p p^{N L / N L}, t(20)=2.80, p=0.011\right)$, and exhibited a preference toward the target quadrant over nontarget quadrants (Additional file 1: Fig. S1a; $A p p^{N L / N L}$, $t(10)=-2.80, p=0.019)$. Neither the number of platform crossings (Fig. 2b) nor proximity to the platform (Fig. 2c; post hoc, WT vs. $A p p^{N L / N L}, p=0.554$ ) differed between $\mathrm{WT}$ and $A p p^{N L / N L}$ mice. The total distance travelled (Fig. 2d) and swimming speed (Fig. 2e) during the test did not differ between WT and $A p p^{N L / N L}$ mice. 
Taken together, these results suggest that spatial memory at 1 day after the last training session was equivalent in $A p p^{N L / N L}$ and WT mice at 24 months of age.

In Probe test 2, the percentage of time spent in the target quadrant did not differ significantly between WT and $A p p^{N L / N L}$ mice (Fig. 2f; post hoc, WT vs. $A p p^{N L / N L}$, $p=0.907) . A p p^{N L / N L}$ mice still spent a significantly higher percentage of time in the target quadrant than predicted by chance (Fig. 2f; $A p p^{N L / N L}, t(20)=5.93, p<0.001$ ), and exhibited a spatial bias toward this quadrant over other quadrants (Additional file 1: Fig. S1b; $A p p^{N L / N L}$, $t(10)=-5.94, p<0.001)$. The number of platform crossings (Fig. $2 \mathrm{~g}$ ) and proximity to the platform (Fig. $2 \mathrm{~h}$; post hoc, WT vs. $\left.A p p^{N L / N L}, p=0.293\right)$ were similar between WT and $A p p^{N L / N L}$ mice, as reflected by total distance travelled (Fig. 2i; post hoc, WT vs. $A p p^{N L / N L}, p=0.844$ ) and swimming speed (Fig. 2j) during the test, indicating that motor capability and motivation were comparable between these genotypes. Taken together, these results suggest that $A p p^{N L / N L}$ mice had normal memory function even 7 days after the last training session. Taken together, these results suggest that $A p p^{N L / N L}$ mice do not exhibit any alterations in spatial learning and memory, even at the age of 24 months.

\section{$A p p^{N L-G-F / N L-G-F}$ mice exhibit aggressive $A \beta$ amyloidosis and reactive gliosis, whereas $A p p^{N L / N L}$ mice do not develop overt $A \beta$ pathology in their brains}

To determine whether cognitive deficits are correlated with $\mathrm{A} \beta$-related brain pathology, we immunostained coronal brain sections from $A p p^{N L-G-F / N L-G-F}, A p p^{N L / N L}$ and WT mice with the anti-A $\beta$ antibody $82 \mathrm{E} 1$, anti-Iba1 antibody as a microglial marker, and anti-GFAP antibody as an astrocytic marker. Intense Iba1 immunoreactivity were clustered around regions of $A \beta$ immunoreactivity both in the cortex (Fig. 3b) and hippocampus (Fig. 3d) of 24-month-old $A p p^{N L-G-F / N L-G-F}$ mice, and high-magnification images in the cortex confirmed accumulation of microglia around the $\mathrm{A} \beta$ plaques (Fig. $3 \mathrm{~b}$, lower panels). $A p p^{N L-G-F / N L-G-F}$ mice also exhibited intense GFAP immunoreactivity in the cortex (Fig. 3c) and hippocampus (Fig. 3e), suggestive of astrogliosis. Higher-magnification images revealed that many reactive astrocytes were present around the $\mathrm{A} \beta$ plaques (Fig. $3 \mathrm{c}$, lower panels). Taken together, these findings indicate that $A p p^{N L-G-F / N L-G-F}$ mice developed extensive microgliosis and astrocytosis associated with the aggressive $A \beta$ plaque formation in their brains.

By sharp contrast, despite extensive analysis, we did not detect any A $\beta$-related pathology in the brains of $A p p^{N L / N L}$ mice at 24 months of age. No $A \beta$ deposits were detected in the cortex (Fig. 3b and c) or hippocampus (Fig. 3d and e), and Ibal and GFAP immunoreactivities were similar between WT and $A p p^{N L / N L}$ mice in both regions (Fig. 3b and $\mathrm{c}$ for cortex; Fig. 3d and e for hippocampus), indicating the absence of reactive gliosis in the brains of $A p p^{N L /}$ ${ }^{N L}$ mice. Taken together, these results suggest that $A p p^{N L /}$ ${ }^{N L}$ mice developed neither $\mathrm{A} \beta$ deposition nor neuroinflammation in the brain, even at 24 months of age.

\section{Discussion}

In this study, we assessed the validity of $A p p^{N L-G-F}$ and $A p p^{N L}$ mice at an advanced age as models for investigating the early phase of AD pathogenesis, based on brain pathologies and performance in a spatial learning and memory task.

Several groups have reported behavioral alterations in cognitive and non-cognitive (social and emotional) domains in $A p p$-KI mice at various ages (summarized in Fig. 4 for $A p p^{N L-G-F / N L-G-F}$ mice, Fig. 5 for $A p p^{N L-F /}$ $N L-F$ mice, and Fig. 6 for $A p p^{N L / N L}$ mice). Among these $A p p-$ KI mice, $A p p^{N L-G-F / N L-G-F}$ mice exhibited the most severe brain pathology, including $\mathrm{A} \beta$ deposition and neuroinflammation (Fig. 3) [10, 11, 20]. However, the general behavioral phenotypes of $A p p$-KI mice described in many published studies are minimal [9], with the exception of robust alterations in emotional domains $[14,21$, 22]. Accordingly, researchers have reached a consensus that the alterations in cognitive abilities of App-KI mice are very mild relative to the phenotypes of other overexpression models $[11,13,21]$. However, these findings are not consistent across studies: for example, in the MWM task, two groups have reported that $A p p^{N L-G-F / N L-G-F}$ mice develop no obvious deficits in spatial learning and memory up to 12 months of age [21, 23], whereas another reported robust learning and memory deficits in $A p p^{N L-G-F / N L-G-F}$ mice at 6 months of age [12]. In this study, to investigate whether $A p p^{N L-G-F}$ mice exhibit deficits in learning and memory at an advanced age, we assessed the performance of $A p p^{N L-G-F / N L-G-F}$ mice in the MWM task at the age of 24 months. Our results revealed that 24-month-old $A p p^{N L-}$ $G-F / N L-G-F$ mice exhibited a significant decline in spatial learning, and also exhibited spatial memory deficits relative to WT mice (Figs. 1 and 2), supporting the idea that sustained $A \beta$-related pathologies in the absence of APP overexpression are capable of inducing cognitive deficits in mice.

Another important finding from this study is that spatial learning and memory in $A p p^{N L / N L}$ mice were comparable to those in WT mice at ages up to 24 months. 

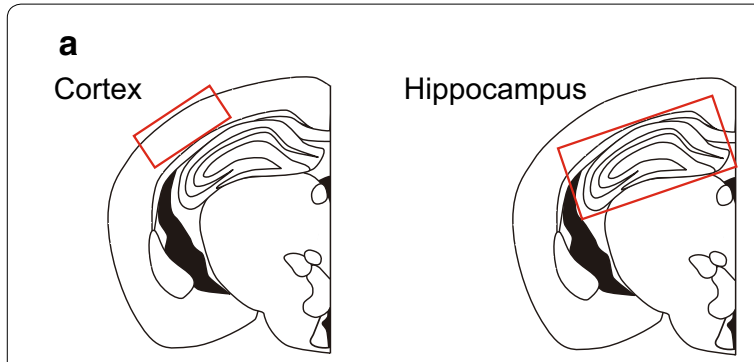

b

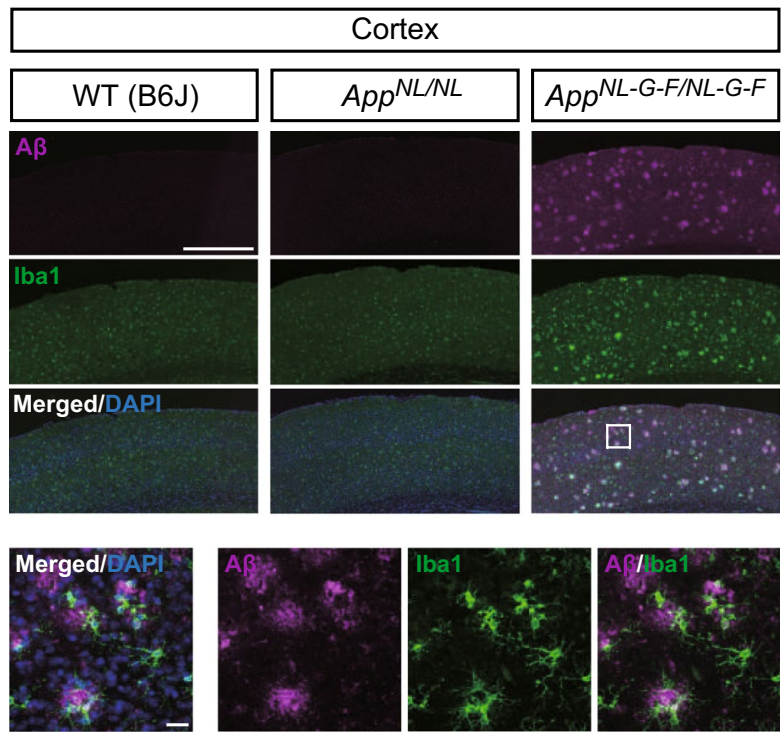

d

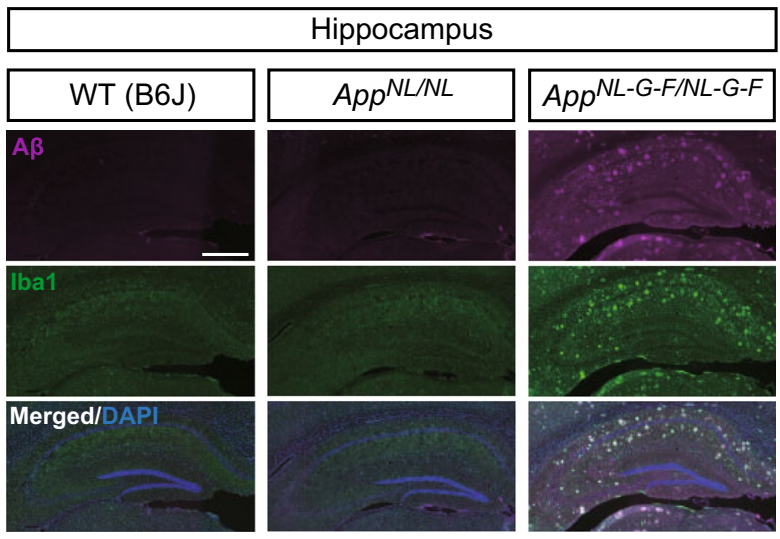

C
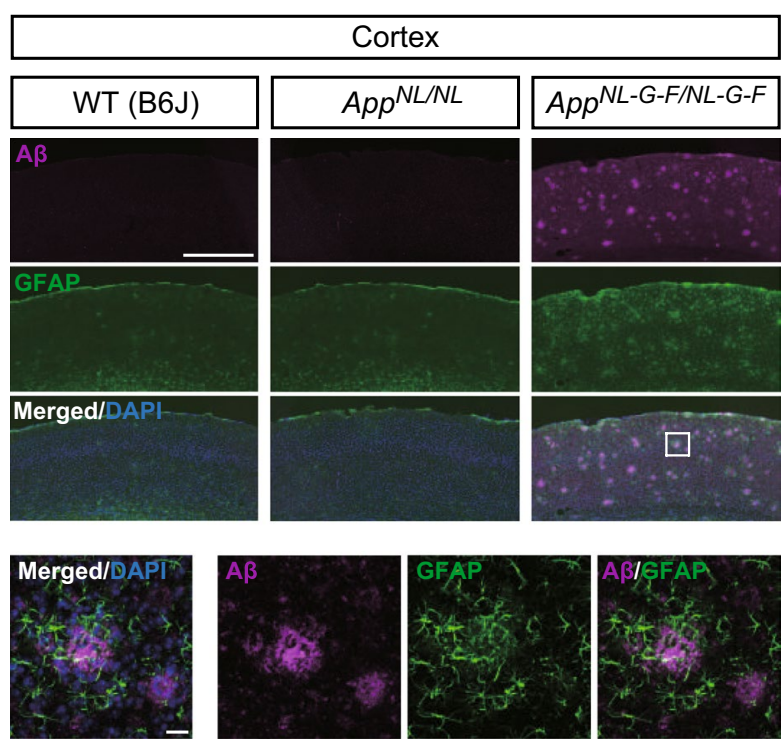

e

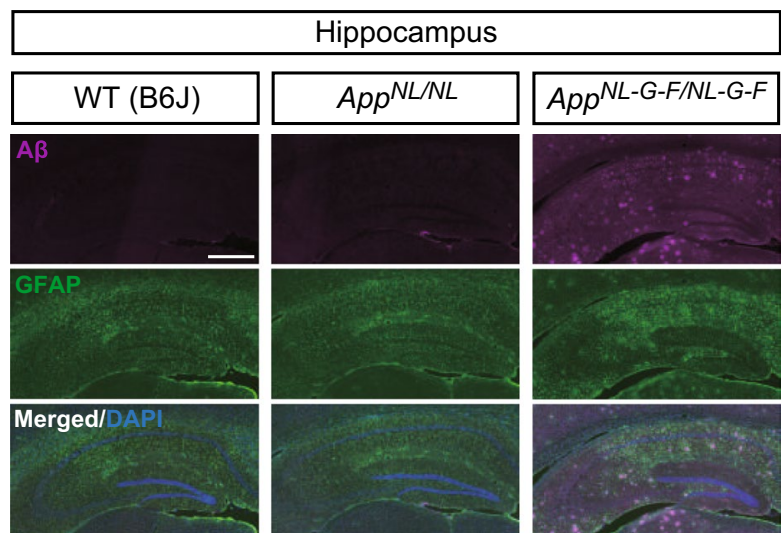

Fig. $3 A \beta$ deposition and reactive gliosis in brains of 24-month-old $A p p^{N L-G-F N L-G-F}$ and $A p p^{N L N L}$ mice. a Red rectangles in the schematic diagrams of mouse brain slice indicated brain regions selected for capturing immunofluorescent images. $\mathbf{b}$-e Representative images of cortical and hippocampal regions from coronal brain sections immunostained with anti-Aß 82 E1 (magenta in $\mathbf{b}-\mathbf{e}$ ), anti-lba1 (green in $\mathbf{b}$ and $\mathbf{d}$ ) and anti-GFAP (green in $\mathbf{c}$ and $\mathbf{e}$ ) were shown (blue in merged images indicated DAPI staining). $\mathbf{b}$ and $\mathbf{c}$ The magnified images captured from enclosed areas by the white rectangles in $A p p^{N L-G-F N L-G-F}$ mice were shown in the bottom panels. b-e App ${ }^{N L-G-F N L-G-F}$ mice exhibited extensive microgliosis and astrocytosis associated with the aggressive $A \beta$ plaque formation in the cortex and hippocampus. b-e $A p p^{N L}$ NL mice developed neither $A \beta$ deposition nor neuroinflammation in the brain. $n=4$ per genotype. Scale bar represents $500 \mu \mathrm{m}$ for low-magnification images $\mathbf{b}-\mathbf{e}$ and $20 \mu \mathrm{m}$ for high-magnification images (bottom panels in $\mathbf{b}$ and $\mathbf{c}$ ) 
Moreover, in sharp contrast to $A p p^{N L-G-F / N L-G-F}$ mice, $A p p^{N L / N L}$ mice did not develop overt brain pathologies, including $A \beta$ deposition and reactive gliosis (Fig. 3), despite overproducing human $A \beta 40$ and $A \beta 42$ in their brains $[10,13]$. These results indicate that introduction of the Swedish mutation in endogenous APP is not sufficient to produce brain pathology or cognitive deficits in mice, and suggest that $A \beta$-related pathology is required to induce these cognitive deficits. These results are consistent with recent studies reporting negligible cognitive deficits and the lack of $\mathrm{A} \beta$ plaque formation in $A p p^{N L / N L}$ mice (Fig. 6) [10, 11, 13, 14, 24].

Familial AD mutations in APP and PSEN1 genes have been utilized to develop mouse models bearing $\mathrm{A} \beta$ pathologies including amyloid plaques and cerebral amyloid angiopathy [2]. The first successful mouse models reproducing $A \beta$ pathologies overexpressed human APP with either a single Swedish [25, 26] or Indiana [27] mutation. Because A $\beta$ aggregation strictly depends on time, concentration, and $A \beta 42 / A \beta 40$ ratio, dozens of mouse lines overexpressing several combinations of $A P P$ and PSEN1 mutations have been created to accelerate the onset of $A \beta$ pathologies in brains [28-30]. These mouse models have made significant contributions to AD research, however, they also suffered from potential offtarget effects caused by either non-physiological overexpression of APP/PSEN1 genes and/or combinations of familial AD mutations, which are not observed in AD patients $[2,9]$. To overcome these issues, KI mouse models with familial AD mutations have been generated [10, $24,31,32]$. To date, however, $A \beta$ pathologies and cognitive deficits were observed only when two or three familial AD mutations were combined [33-35]. This study provides further evidence that a single Swedish mutation in $A P P$ is not sufficient to reproduce $\mathrm{A} \beta$ pathologies and cognitive deficits in mice. Our results also highlight the importance of age-associated factors to promote $A \beta$ depositions in brains, and suggest that KI mouse models with a single familial AD mutation such as $A p p^{N L / N L}$ mice may be valuable tools to truly understand the biology of APP mutations in AD pathogenesis. Such studies may reveal novel therapeutic targets not only for familial but also for sporadic cases of AD.

\section{Conclusions}

$A p p^{N L-G-F / N L-G-F}$ mice are an excellent model for investigating the mechanisms underlying cognitive deficits caused by A $\beta$-related pathologies, as well as for testing potential AD therapeutics. $A p p^{N L / N L}$ mice represent a valuable model for exploring the critical factors involved in $\mathrm{A} \beta$ plaque formation and associated brain pathologies.

\section{Methods}

\section{Animals}

The original lines of $A p p$-KI $\left(A p p^{N L-G-F / N L-G-F}\right.$ and $A p p^{N L /}$ ${ }^{N L}$ ) mice on a C57BL/6J genetic background [10] were obtained from RIKEN Center for Brain Science (Wako, Japan) and maintained at the Institute for Animal Experimentation in National Center for Geriatrics and Gerontology as described previously [14]. After weaning, all mice were housed socially in same-sex groups and only male mice were used for the experiments with mixed genotypes. All handling and experimental procedures were performed in accordance with the Guidelines for the Care of Laboratory Animals of National Center for Geriatrics and Gerontology (Obu, Japan).

\section{Morris water maze task}

All experiments were performed in a white circular pool (1.0 $\mathrm{m}$ in diameter; O'hara \& Co., Tokyo, Japan) with a light intensity on the center of the pool of approximately $80 \mathrm{~lx}$. Water temperature was maintained at $24 \pm 1{ }^{\circ} \mathrm{C}$ and was made opaque using nontoxic white paint during hidden training sessions and probe tests.

First, 24-month-old mice ( $n=11-17 /$ genotype) were individually handled for 3 days before starting the experiment to acclimate them to the introduction and removal of the pool. After the habituation period, mice were subjected to 4-day visible training sessions (four trials per day, with an intertrial interval of approximately $15 \mathrm{~min}$ ) (Fig. 1a), in which a platform $(10 \mathrm{~cm}$ in diameter) was made visible by attaching a black cubic landmark. The aim of the visible training was to exclude mice with motor, visual or motivational impairments. If the mouse found the platform within a 2-min time limit, the mouse remained there for $20 \mathrm{~s}$. If not, the mouse was gently guided towards the platform before staying on it. After the 20-s period on the platform, mice were placed in the cage heated by a heating pad to dry and then transported

\footnotetext{
(See figure on next page.)

Fig. 4 Summary of published behavioral data in $A p p^{N L-G-F / N L-G-F}$ mice. Blue cells represent that App ${ }^{N L-G-F / N L-G-F}$ mice performed the same as control lines, while red cells represent that $A p p^{N L-G-F / N L-G-F}$ mice behaved differently from control lines. Age (months) is presented in top of the figure. The "Sex" column indicates sex of mice used in the experiments; "M", "F" and "M+F" means only male, only female and both sexes, respectively. The "vs. Control" column indicates control strain used in the experiments; B6J represents wild-type C57BL/6J strain. The "Ref" column indicates references corresponding to the data. The following references are listed in the column; Latif-Hernandez et al. [21], Masuda et al. [11], Mehla et al. [12], Pervolaraki et al. [22], Saito et al. [10], Sakakibara et al. [14], Whyte et al. [23]
} 


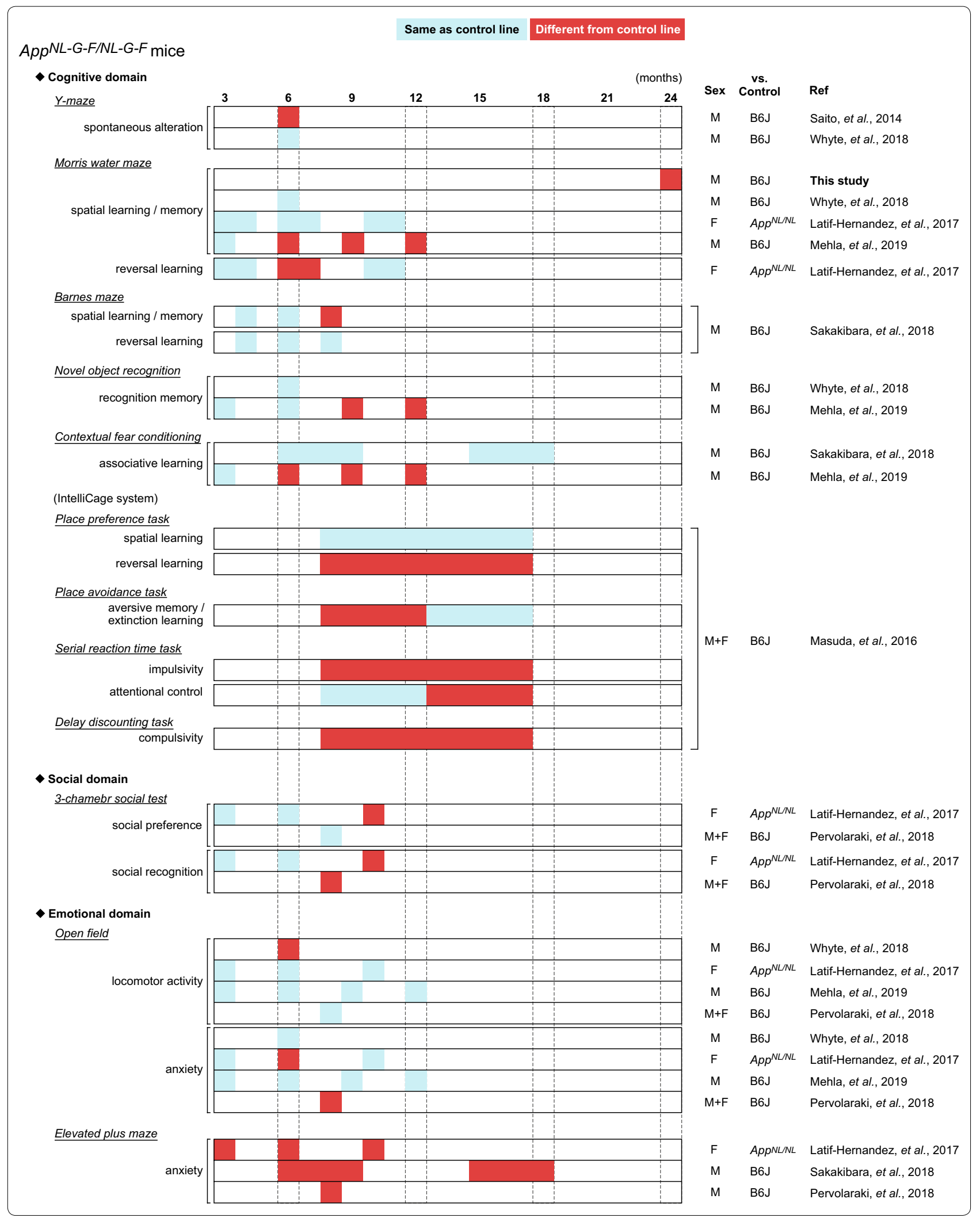




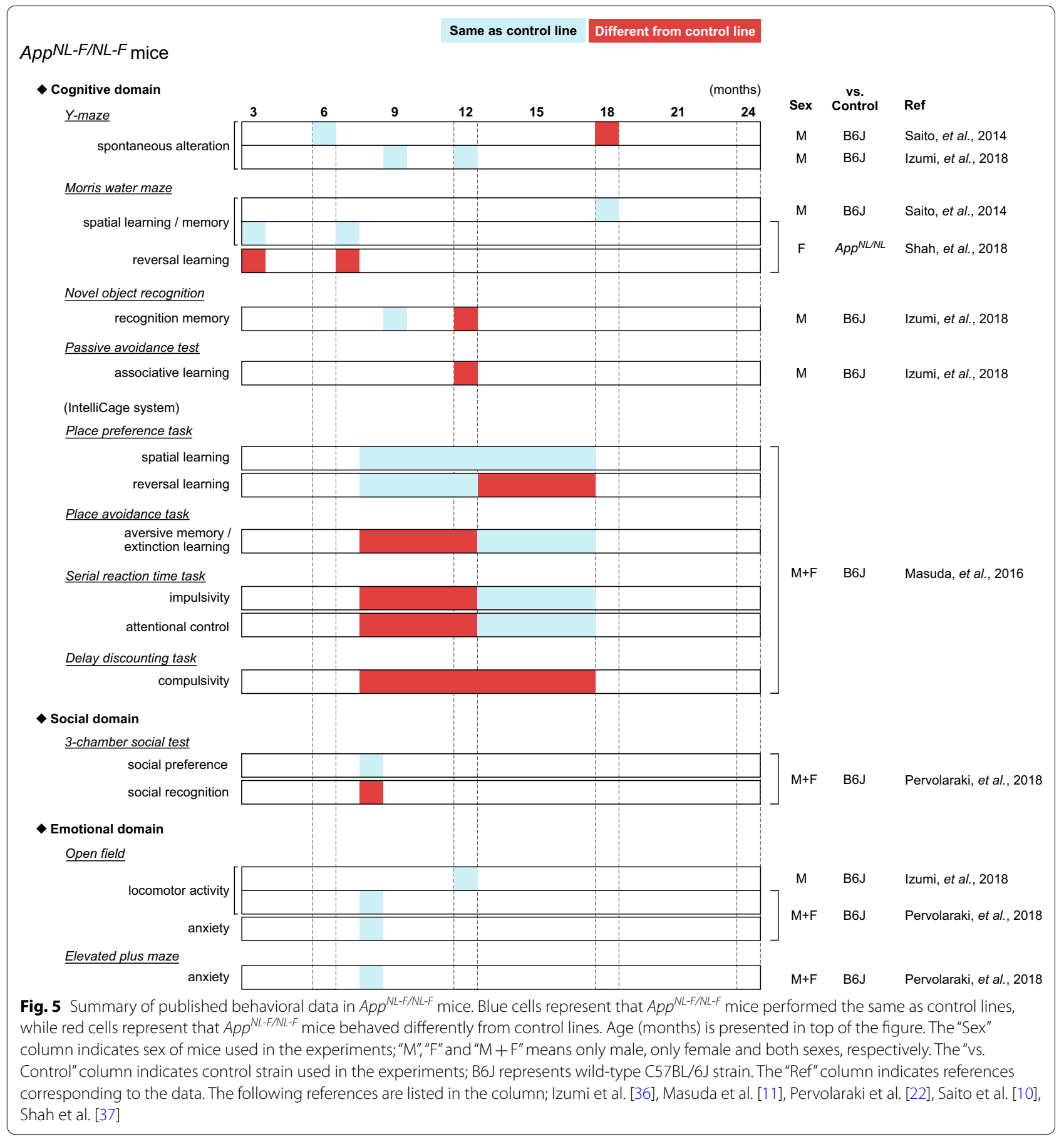

back to their home cage. The location of the platform and the start position were changed randomly in each trial. For each trial, latency to reach the platform (s), swimming distance $(\mathrm{cm})$ and swimming speed $(\mathrm{cm} / \mathrm{s})$ were automatically measured using TimeMWM software (O'hara \& Co., Tokyo, Japan).
Following the visible training sessions, the mice were subjected to 7-day hidden training sessions (four trials per day, with an intertrial interval of approximately $20 \mathrm{~min}$ ) (Fig. 1a), in which the platform was placed 0.8 $1.0 \mathrm{~cm}$ below the water surface. Four distinct objects of different geometry were used around the pool as spatial cues. At the end of the trial, either when the mouse had 


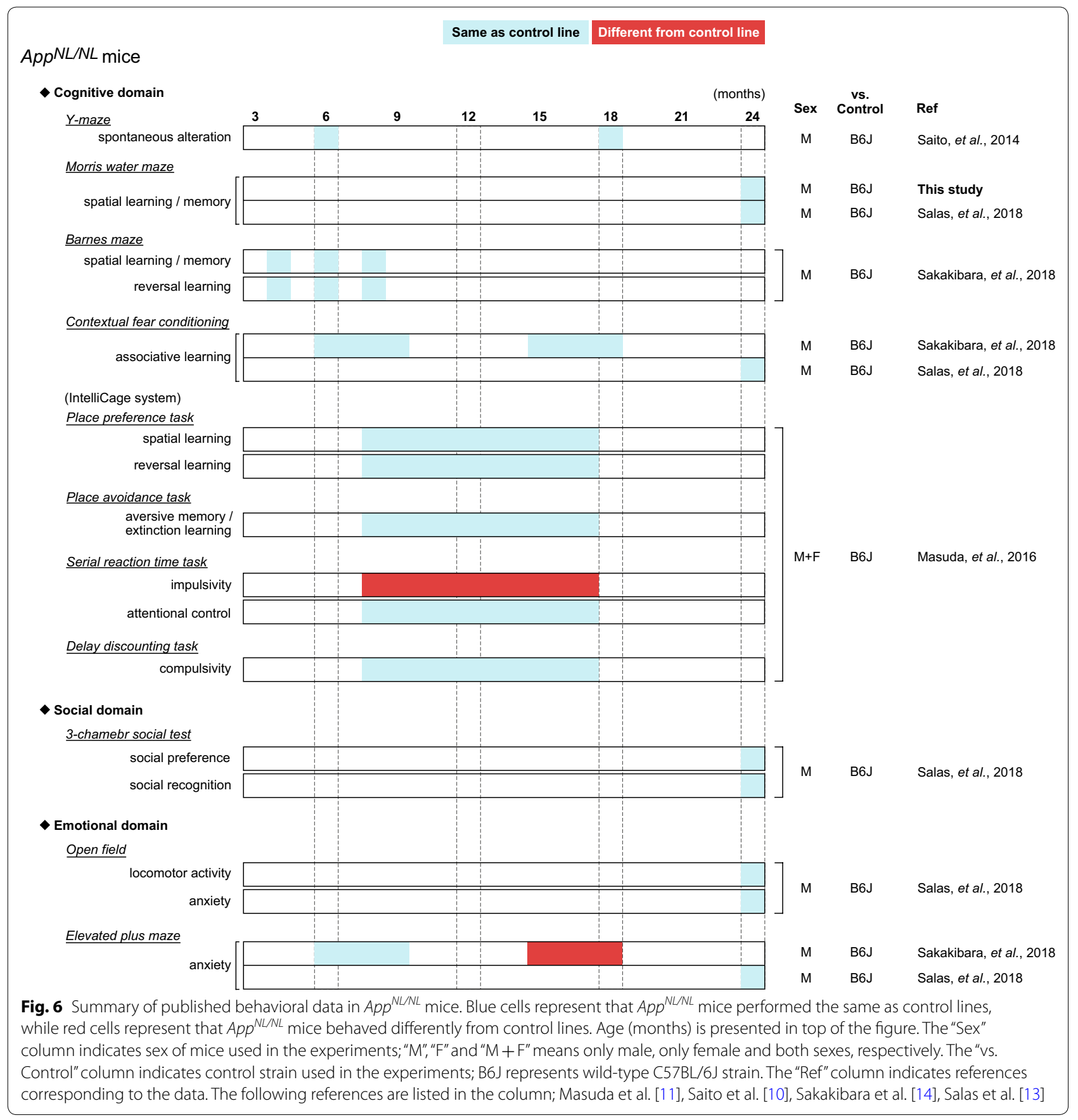

found the platform or when a 60-s time limit had elapsed, mice were allowed to rest on the platform for $15 \mathrm{~s}$. Then, mice were placed in the cage heated by a heating pad to dry before returning to their home cage. The start position was changed randomly to avoid track memorization, while the location of the platform was fixed throughout the experiment. Latency $(\mathrm{s})$ and distance travelled $(\mathrm{cm})$ to reach the platform and swimming speed $(\mathrm{cm} / \mathrm{s})$ were also measured by the software. To quantify the efficiency of the strategy pursued in reaching the platform, path efficiency was calculated by dividing the distance between the first and last locations by the total distance travelled (Path efficiency $=$ Distance between the starting point and the final point (the location of the platform)/Total distance travelled).

To confirm that this spatial task was acquired based on navigation by distal cues, two probe tests were conducted as following: the first probe test at one day after 
the sixth session (Probe test 1 ) and the second probe test at 7 days after the seventh session (Probe test 2) of the hidden training (Fig. 1a). In these tests, the platform was removed from the pool and mice were allowed to search the platform for $60 \mathrm{~s}$. Time spent in each quadrant (TQ; target quadrant, OQ; opposite quadrant; RQ; right quadrant, LQ; left quadrant) (s), number of crossings over the platform location and average proximity to the platform $(\mathrm{cm})$ were measured by the software. Total distance travelled $(\mathrm{cm})$ and swimming speed $(\mathrm{cm} / \mathrm{s})$ were also measured to rule out the involvement of motor function and motivation to search the platform as confounding factors.

After the behavioral experiments, these mice were administered intraperitoneally with the combined agent with medetomidine $(0.3 \mathrm{mg} / \mathrm{kg})$, midazolam $(4 \mathrm{mg} / \mathrm{kg})$ and butorphanol $(5 \mathrm{mg} / \mathrm{kg})$. The whole brain tissues were collected and subjected to immunohistochemistry and other experiments.

\section{Immunohistochemistry}

Immunohistochemical staining was performed in male mice of the 3 genotypes ( $n=4 /$ genotype) to examine the degree of $A \beta$ amyloidosis and reactive gliosis in cortical and hippocampal regions (Fig. 3a). During maintenance of anesthesia with the same cocktail combination (medetomidine $(0.3 \mathrm{mg} / \mathrm{kg})+$ midazolam $(4 \mathrm{mg} /$ $\mathrm{kg})+$ butorphanol $(5 \mathrm{mg} / \mathrm{kg}))$, mice were then perfused intracardially with ice-cold saline followed by $4 \%$ paraformaldehyde (PFA) in $0.1 \mathrm{M}$ phosphate buffer (PB). The whole brains were collected and immersed in the same fixative solution at $4{ }^{\circ} \mathrm{C}$ overnight. For cryoprotection, the fixed brains were transferred into $20 \%$ and then $30 \%$ sucrose in $0.1 \mathrm{M} \mathrm{PB}$ at $4{ }^{\circ} \mathrm{C}$ until the tissues sank. Brains were sliced coronally into $25-\mu \mathrm{m}$ free-floating sections using a cryostat (Leica CM3050; Leica Microsystems, Wetzlar, Germany). For antigen retrieval, sections were incubated with $70 \%$ formic acid at $5 \mathrm{~min}$. After wash with PBS containing $0.1 \%$ Triton X-100 (PBS-T), the sections were blocked in a buffer containing $5 \%$ normal goat serum, $0.5 \%$ bovine serum albumin (BSA) and $0.3 \%$ Triton $\mathrm{X}-100$ in PBS for $1 \mathrm{~h}$, and then incubated overnight at $4{ }^{\circ} \mathrm{C}$ with primary antibodies in a dilution buffer containing 3\% normal goat serum, $0.5 \%$ BSA and $0.3 \%$ Triton X-100 in PBS. The following primary antibodies were used: mouse anti-A $\beta$ 82E1 (1:200; 10323; IBL, Gunma, Japan), rabbit anti-Iba1 (1:500; 019-19741; Wako, Osaka, Japan) and rabbit anti-GFAP (1:500; ROI003; SHIMA Laboratories Co., Ltd., Tokyo, Japan). After three washes with PBS-T were given, the sections were then incubated for $2-3 \mathrm{~h}$ with the following secondary antibodies in the dilution buffer; Alexa Fluor 594 goat anti-mouse IgG (1:500; ab150116; Abcam) and Alexa Fluor 488 goat antirabbit IgG (1:500; ab150077; Abcam). After three washes with PBS-T, the sections were incubated with DAPI $(2 \mu \mathrm{g} / \mathrm{ml})$ at $5 \mathrm{~min}$ and mounted in Aqua-Poly/Mount (Polysciences Inc., Warrington, USA). Immunofluorescence images of the sections were captured using a florescence microscope (BZ-9000; Keyence, Osaka, Japan) or a confocal laser-scanning microscope (LSM 780; Carl Zeiss, Oberkochen, Germany).

\section{Statistical analysis}

As previously described [14], statistical differences between genotypes against behavioral parameters with one dependent variable were determined by repeatedmeasures analysis of variance (ANOVA). When necessary, Greenhouse-Geisser estimates of sphericity were used to correct for degrees of freedom. Bonferroni post hoc comparisons were used to evaluate group differences. For the comparisons of multiple means with genotypes as one independent variable, one-way ANOVA followed by the Tukey's post hoc tests was used. Onesample $t$-test was used to compare performance on the probe test of the MWM task against chance level (25\%). Differences of the percentage of time spent between target and non-target quadrants during probe tests were evaluated using paired $t$-test. Data are presented as mean \pm SEM. All alpha levels were set at 0.05 .

\section{Additional file}

Additional file 1: Figure S1. Quadrant preference shown by each genotype during probe tests in the Morris water maze task. (a) In Probe test 1, both $A p p^{N L-G-F / N L-G-F}$ and $A p p^{N L / N L}$ mice exhibited a preference for the target quadrant over non-target quadrants. (b) In Probe test 2, App ${ }^{\mathrm{NL}-G-F /}$ ${ }_{N L-G-F}$ mice did not exhibit a spatial bias toward the target quadrant over non-target quadrants, while $A p p^{N L / N L}$ mice exhibited a preference toward the target quadrant. Dotted lines indicate chance level (25\%). $n=17$ WT (B6J), $\mathrm{n}=11 \mathrm{Ap} p^{N L / N L}, \mathrm{n}=16 \mathrm{Ap} p^{N L-G-F / N L-G-F} \cdot{ }^{\S} p<0.05,{ }^{\S \S} p<0.01,{ }^{\S \S \S} p<0.001$, target quadrant versus average of non-target quadrants.

\section{Abbreviations}

AD: Alzheimer's disease; APP: amyloid precursor protein; A $\beta$ : amyloid- $\beta$; ANOVA: analysis of variance; GFAP: glial fibrillary acidic protein; Iba1: ionized calcium binding adaptor molecule 1; Kl: knock-in; MWM: Morris water maze; WT: wild-type.

\section{Authors' contributions}

YS, MS and KMI conceived the experiments, YS conducted the experiment and analyzed the data, YS, MS and KMI interpret the data. TS and TCS provided the App-KI mice and interpret the data. YS, MS and KMI wrote the paper. All authors read and approved the final manuscript.

\section{Author details}

${ }^{1}$ Department of Alzheimer's Disease Research, Center for Development of Advanced Medicine for Dementia, National Center for Geriatrics and Gerontology, Obu, Aichi 474-8511, Japan. ${ }^{2}$ Laboratory for Proteolytic Neuroscience, RIKEN Center for Brain Science, Wako, Saitama 351-0198, Japan. ${ }^{3}$ Department of Experimental Gerontology, Graduate School of Pharmaceutical Sciences, Nagoya City University, Nagoya 467-8603, Japan. 


\section{Acknowledgements}

We thank Sachie Chikamatsu and Kimi Takei for technical assistance and Drs. Nobuyuki Kimura and Tetsuya Kimura for the comments on the data. Schematics of mouse brain slice are reproduced by curtesy of Database Center for Life Science (@ 2016 DBCLS TogoTV).

\section{Competing interests}

The authors declare that they have no competing interests.

\section{Availability of data and materials}

The datasets used and/or analyzed during the current study are available from the corresponding authors on reasonable request.

\section{Consent for publication}

Not applicable.

\section{Ethics approval and consent to participate}

All animal experimental procedures were performed according to the $\mathrm{NIH}$ Guide for the Care and Use of Laboratory Animals and other national regulations and policies with the approval of the Animal Care and Use Committee at National Center for Geriatrics and Gerontology, Japan (Approval number: 30-1).

\section{Funding}

This study was supported by JSPS KAKENHI Grant No. JP18K15381 (to Y.S.), the Research Funding for Longevity Science from National Center for Geriatrics and Gerontology, Japan, Grant No. 28-26, Takeda Science Foundation (JP) and DAIKO FOUNDATION (JP) (to K.M.I.)

\section{Publisher's Note}

Springer Nature remains neutral with regard to jurisdictional claims in published maps and institutional affiliations.

Received: 28 January 2019 Accepted: 15 March 2019

Published online: 20 March 2019

\section{References}

1. Gotz J, Bodea LG, Goedert M. Rodent models for Alzheimer disease. Nat Rev Neurosci. 2018;19(10):583-98.

2. Jankowsky JL, Zheng $\mathrm{H}$. Practical considerations for choosing a mouse model of Alzheimer's disease. Mol Neurodegener. 2017;12:89.

3. Kitazawa M, Medeiros R, Laferla FM. Transgenic mouse models of Alzheimer disease: developing a better model as a tool for therapeutic interventions. Curr Pharm Des. 2012;18(8):1131-47.

4. Lalonde R, Fukuchi K, Strazielle C. APP transgenic mice for modelling behavioural and psychological symptoms of dementia (BPSD). Neurosci Biobehav Rev. 2012;36(5):1357-75

5. Webster SJ, Bachstetter AD, Nelson PT, Schmitt FA, Van Eldik LJ. Using mice to model Alzheimer's dementia: an overview of the clinical disease and the preclinical behavioral changes in 10 mouse models. Front Genet. 2014:5:88.

6. Balducci C, Forloni G. APP transgenic mice: their use and limitations. Neuromolecular Med. 2011;13(2):117-37.

7. Gidyk DC, Deibel SH, Hong NS, McDonald RJ. Barriers to developing a valid rodent model of Alzheimer's disease: from behavioral analysis to etiological mechanisms. Front Neurosci. 2015;9:245.

8. Rice HC, de Malmazet D, Schreurs A, Frere S, Van Molle I, Volkov AN, Creemers E, Vertkin I, Nys J, Ranaivoson FM, et al. Secreted amyloidbeta precursor protein functions as a GABABR1a ligand to modulate synaptic transmission. Science. 2019;363(6423):eaao4827.

9. Sasaguri H, Nilsson P, Hashimoto S, Nagata K, Saito T, De Strooper B, Hardy J, Vassar R, Winblad B, Saido TC. APP mouse models for Alzheimer's disease preclinical studies. EMBO J. 2017;36(17):2473-87.

10. Saito T, Matsuba Y, Mihira N, Takano J, Nilsson P, Itohara S, Iwata N, Saido TC. Single App knock-in mouse models of Alzheimer's disease. Nat Neurosci. 2014;17(5):661-3.
11. Masuda A, Kobayashi Y, Kogo N, Saito T, Saido TC, Itohara S. Cognitive deficits in single App knock-in mouse models. Neurobiol Learn Mem 2016:135:73-82.

12. Mehla J, Lacoursiere SG, Lapointe $V$, McNaughton BL, Sutherland RJ, McDonald RJ, Mohajerani MH. Age-dependent behavioral and biochemical characterization of single APP knock-in mouse (APP(NL-G-F/ NL-G-F)) model of Alzheimer's disease. Neurobiol Aging. 2019;75:25-37.

13. Salas IH, Callaerts-Vegh Z, D'Hooge R, Saido TC, Dotti CG, De Strooper $B$. Increased insoluble amyloid-beta induces negligible cognitive deficits in old AppNL/NL Knock-In Mice. J Alzheimers Dis. 2018;66(2):801-9.

14. Sakakibara Y, Sekiya M, Saito T, Saido TC, lijima KM. Cognitive and emotional alterations in App knock-in mouse models of Abeta amyloidosis. BMC Neurosci. 2018;19:46.

15. Puzzo D, Gulisano W, Palmeri A, Arancio O. Rodent models for Alzheimer's disease drug discovery. Expert Opin Drug Discov. 2015;10(7):703-11.

16. Illouz T, Madar R, Louzoun Y, Griffioen KJ, Okun E. Unraveling cognitive traits using the Morris water maze unbiased strategy classification (MUSTC) algorithm. Brain Behav Immun. 2016;52:132-44.

17. Timic T, Joksimovic S, Milic M, Divljakovic J, Batinic B, Savic MM. Midazolam impairs acquisition and retrieval, but not consolidation of reference memory in the Morris water maze. Behav Brain Res. 2013;241:198-205.

18. Gallagher M, Burwell R, Burchinal M. Severity of spatial learning impairment in aging: development of a learning index for performance in the Morris water maze. Behav Neurosci. 1993;107(4):618-26.

19. Maei HR, Zaslavsky K, Teixeira CM, Frankland PW. What is the most sensitive measure of water maze probe test performance? Front Integr Neurosci. 2009;3:4.

20. Saito T, Saido TC. Neuroinflammation in mouse models of Alzheimer's disease. Clin Exp Neuroimmunol. 2018;9(4):211-8.

21. Latif-Hernandez A, Shah D, Craessaerts K, Saido T, Saito T, De Strooper B, Van der Linden A, D'Hooge R. Subtle behavioral changes and increased prefrontal-hippocampal network synchronicity in APP(NL-G-F) mice before prominent plaque deposition. Behav Brain Res. 2017; . https://doi. org/10.1016/j.bbr.2017.11.017.

22. Pervolaraki E, Hall SP, Foresteire D, Saito T, Saido TC, Whittington MA, Lever C, Dachtler J. Insoluble Abeta overexpression in an App knock-in mouse model alters microstructure and gamma oscillations in the prefrontal cortex, and social and anxiety-related behaviours. bioRxiv. 2018.

23. Whyte LS, Hemsley KM, Lau AA, Hassiotis S, Saito T, Saido TC, Hopwood JJ, Sargeant TJ. Reduction in open field activity in the absence of memory deficits in the App(NL-G-F) knock-in mouse model of Alzheimer's disease. Behav Brain Res. 2018;336:177-81.

24. Reaume AG, Howland DS, Trusko SP, Savage MJ, Lang DM, Greenberg $\mathrm{BD}$, Siman R, Scott RW. Enhanced amyloidogenic processing of the beta-amyloid precursor protein in gene-targeted mice bearing the Swedish familial Alzheimer's disease mutations and a "humanized" Abeta sequence. J Biol Chem. 1996;271(38):23380-8.

25. Hsiao K, Chapman P, Nilsen S, Eckman C, Harigaya Y, Younkin S, Yang F, Cole G. Correlative memory deficits, Abeta elevation, and amyloid plaques in transgenic mice. Science. 1996;274(5284):99-102.

26. Sturchler-Pierrat C, Abramowski D, Duke M, Wiederhold KH, Mistl C, Rothacher S, Ledermann B, Burki K, Frey P, Paganetti PA, et al. Two amyloid precursor protein transgenic mouse models with Alzheimer disease-like pathology. Proc Natl Acad Sci USA. 1997;94(24):13287-92.

27. Games D, Adams D, Alessandrini R, Barbour R, Berthelette P, Blackwell C, Carr T, Clemens J, Donaldson T, Gillespie F, et al. Alzheimer-type neuropathology in transgenic mice overexpressing V717F beta-amyloid precursor protein. Nature. 1995;373(6514):523-7.

28. Jankowsky JL, Fadale DJ, Anderson J, Xu GM, Gonzales V, Jenkins NA, Copeland NG, Lee MK, Younkin LH, Wagner SL, et al. Mutant presenilins specifically elevate the levels of the 42 residue beta-amyloid peptide in vivo: evidence for augmentation of a 42 -specific gamma secretase. Hum Mol Genet. 2004;13(2):159-70.

29. Oakley H, Cole SL, Logan S, Maus E, Shao P, Craft J, Guillozet-Bongaarts A, Ohno M, Disterhoft J, Van Eldik L, et al. Intraneuronal beta-amyloid aggregates, neurodegeneration, and neuron loss in transgenic mice with five familial Alzheimer's disease mutations: potential factors in amyloid plaque formation. J Neurosci. 2006;26(40):10129-40. 
30. Radde R, Bolmont T, Kaeser SA, Coomaraswamy J, Lindau D, Stoltze L, Calhoun ME, Jaggi F, Wolburg H, Gengler S, et al. Abeta42-driven cerebral amyloidosis in transgenic mice reveals early and robust pathology. EMBO Rep. 2006;7(9):940-6.

31. Guo Q, Fu W, Sopher BL, Miller MW, Ware CB, Martin GM, Mattson MP. Increased vulnerability of hippocampal neurons to excitotoxic necrosis in presenilin-1 mutant knock-in mice. Nat Med. 1999;5(1):101-6.

32. Siman R, Reaume AG, Savage MJ, Trusko S, Lin YG, Scott RW, Flood DG. Presenilin-1 P264L knock-in mutation: differential effects on abeta production, amyloid deposition, and neuronal vulnerability. J Neurosci. 2000;20(23):8717-26.

33. Flood DG, Reaume AG, Dorfman KS, Lin YG, Lang DM, Trusko SP, Savage MJ, Annaert WG, De Strooper B, Siman R, et al. FAD mutant PS-1 genetargeted mice: increased A beta 42 and A beta deposition without APP overproduction. Neurobiol Aging. 2002;23(3):335-48.

34. Kohler C, Ebert U, Baumann K, Schroder H. Alzheimer's disease-like neuropathology of gene-targeted APP-SLXPS1 mut mice expressing the amyloid precursor protein at endogenous levels. Neurobiol Dis. 2005;20(2):528-40.

35. Li H, Guo Q, Inoue T, Polito VA, Tabuchi K, Hammer RE, Pautler RG, Taffet $\mathrm{GE}$, Zheng H. Vascular and parenchymal amyloid pathology in an Alzheimer disease knock-in mouse model: interplay with cerebral blood flow. Mol Neurodegener. 2014;9:28.

36. Izumi H, Shinoda Y, Saito T, Saido TC, Sato K, Yabuki Y, Matsumoto Y, Kanemitsu Y, Tomioka Y, Abolhassani N, et al. The disease-modifying drug candidate, SAK3 improves cognitive impairment and inhibits amyloid beta deposition in app knock-in mice. Neuroscience. 2018;377:87-97.

37. Shah D, Latif-Hernandez A, De Strooper B, Saito T, Saido T, Verhoye M, D'Hooge R, Van der Linden A. Spatial reversal learning defect coincides with hypersynchronous telencephalic BOLD functional connectivity in APP(NL-F/NL-F) knock-in mice. Sci Rep. 2018;8:6264.
Ready to submit your research? Choose BMC and benefit from:

- fast, convenient online submission

- thorough peer review by experienced researchers in your field

- rapid publication on acceptance

- support for research data, including large and complex data types

- gold Open Access which fosters wider collaboration and increased citations

- maximum visibility for your research: over 100M website views per year

At BMC, research is always in progress.

Learn more biomedcentral.com/submissions 